\title{
Vasopressin reversal of phenoxybenzamine-induced hypotension after the Norwood procedure
}

\author{
Stacy B. O'Blenes, MD, MSc, ${ }^{\text {a }}$ Nathalie Roy, MD, ${ }^{a}$ Igor Konstantinov, MD, ${ }^{a}$ Desmond Bohn, MB, BCh, ${ }^{\text {b }}$ and \\ Glen S. Van Arsdell, MD, ${ }^{a}$ Toronto, Ontario, Canada
}

$\mathrm{T}$

he vasodilator phenoxybenzamine has been reported to assist in balancing the pulmonary and systemic circulations, thereby improving systemic oxygen delivery after the Norwood procedure. ${ }^{1}$ For this reason phenoxybenzamine is part of our routine postoperative management strategy for infants undergoing the Norwood procedure. One potential problem with phenoxybenzamine, however, is prolonged vasodilation related to irreversible blockade of the $\alpha$-adrenergic receptor. ${ }^{2}$ We have observed occasional profound hypotension associated with peripheral vasodilation that is refractory to standard vasopressor therapy. Vasopressin is an alternative vasoconstricting agent that does not act through the $\alpha$-adrenergic receptor and has a relatively short half-life. ${ }^{3}$ We report its use as an effective treatment for severe hypotension in an infant receiving phenoxybenzamine after a Norwood procedure.

\section{Clinical Summary}

On day 8 after birth, a 3.5-kg male infant with hypoplastic left heart syndrome underwent the Norwood procedure. Phenoxybenzamine (GlaxoSmithKline, Mississauga, Ontario) at $0.25 \mathrm{mg} / \mathrm{kg}$ was given at the start of cardiopulmonary bypass. Hypothermic regional perfusion was used for cerebral protection during aortic arch reconstruction. An oximetric catheter was placed directly in the superior vena cava for continuous monitoring of systemic venous oxygen saturation. The sternum was stented open according to our standard protocol, and the skin was closed.

Initial postoperative management included milrinone at 0.66 $\mu \mathrm{g} /(\mathrm{kg} \cdot \mathrm{min})$, dopamine $7.5 \mu \mathrm{g} /(\mathrm{kg} \cdot \mathrm{min})$, and sodium nitroprusside $3 \mu \mathrm{g} /(\mathrm{kg} \cdot \mathrm{min})$. A phenoxybenzamine infusion $(1 \mathrm{mg} /[\mathrm{kg} \cdot \mathrm{d}])$ was started 6 hours after the operation. Phenoxybenzamine was discontinued 23 hours after the operation, and a norepinephrine infusion was started because of hypotension and anuria with clinical and biochemical evidence of excellent systemic perfusion (Figure 1). Blood pressure did not improve with norepinephrine infusion, and the infant became more tachycardic (average heart

\footnotetext{
From the Division of Cardiovascular Surgery a and the Department of Critical Care Medicine, ${ }^{\mathrm{b}}$ The Hospital for Sick Children and the University of Toronto, Toronto, Ontario, Canada.

Received for publication Dec 7, 2001; accepted for publication Dec 11, 2001.

Address for reprints: Glen S. Van Arsdell, MD, The Division of Cardiovascular Surgery, The Hospital for Sick Children, 555 University Ave, Suite 1525, Toronto, Ontario, Canada, M5G 1X8 (E-mail: glen.vanarsdell@sickkids.ca).

J Thorac Cardiovasc Surg 2002;123:1012-3

Copyright (C) 2002 by The American Association for Thoracic Surgery

$0022-5223 / 2002 \$ 35.00+0 \quad \mathbf{1 2 / 5 4 / 1 2 2 2 0 7}$

doi: $10.1067 / \mathrm{mtc} .2002 .122207$
}

rate increased from 169 to 175 beats/min). Vasopressin (Pharmaceutical Partners of Canada Inc, Toronto, Ontario) at 0.0003 to $0.0006 \mathrm{U} /(\mathrm{kg} \cdot \mathrm{min})$ was started 31 hours after the operation for refractory hypotension and persistent anuria despite norepinephrine infusion. Blood pressure improved, and spontaneous urinary output resumed. Average heart rate decreased to 167 beats/min on discontinuation of norepinephrine. The pulmonary/systemic blood flow ratio $(\dot{\mathrm{Q}} / \mathrm{p})$ calculated by assuming a pulmonary venous saturation of $96 \%$ was 0.85 prior to starting vasopressin therapy. $\dot{\mathrm{Q}} / \mathrm{p}$ had climbed to 1.8 before discontinuation of vasopressin therapy 37 hours later. Delayed sternal closure was accomplished on postoperative day 5 , and the patient was discharged home 11 days later.

\section{Discussion}

Phenoxybenzamine reduces systemic vascular resistance, causing hypotension by blocking smooth muscle cell $\alpha$-adrenergic receptors. Because phenoxybenzamine covalently binds to the $\alpha$-adrenergic receptor, it leads to complete and irreversible blockade. Norepinephrine and other $\alpha$-agonists therefore have impaired efficacy in the presence of phenoxybenzamine (Figure 2). Return of sensitivity to catecholamines depends on synthesis of new receptors and may take several days. ${ }^{2}$ Vasopressin has recently been described as an alternative vasoconstricting agent for children with vasodilatory shock after cardiac surgery. ${ }^{4}$ Vasopressin acts on the $\mathrm{V} 1$ receptor of smooth muscle cells ${ }^{5}$ rather than the $\alpha$-adrenergic receptor and is therefore expected to have preserved activity even in the presence of phenoxybenzamine (Figure 2). In addition, vasopressin has a relatively short half-life of 10 to 35 minutes. ${ }^{3}$

The infant we described here had severe hypotension that was refractory to norepinephrine, presumably as a result of $\alpha$-blockade by phenoxybenzamine. The institution of vasopressin therapy was associated with rapidly improving blood pressure and return of renal function. However, these beneficial effects occurred at the expense of a predictable increase in $\dot{Q} / \mathrm{p}$. The rising $\mathrm{Q} / \mathrm{p}$ was most likely related to systemic vascular resistance elevation, but it may have been further influenced by the pulmonary vasodilation that may occur with low-dose vasopressin. ${ }^{3}$ Despite the negative impact of vasopressin on $\dot{Q} / \mathrm{p}$ and the arterial-venous oxygen saturation difference, this patient did not show clinical evidence of impaired cardiac output and did not have lactic acidosis (Figure 1). In contrast to norepinephrine, which stimulates cardiac $\beta$-adrenergic receptors, vasopressin was not associated with increased heart rate and therefore may have had less impact on myocardial oxygen consumption. A syndrome of inappropriate antidiuretic hormone as a result of exogenous vasopressin administration did not occur in this infant. A paradoxic improvement in urinary output, as seen in this case (Figure 1), does occur in certain vasodilatory states. ${ }^{3}$

Any potential benefit of vasopressin therapy must be balanced against possible adverse effects, including complications of severe 


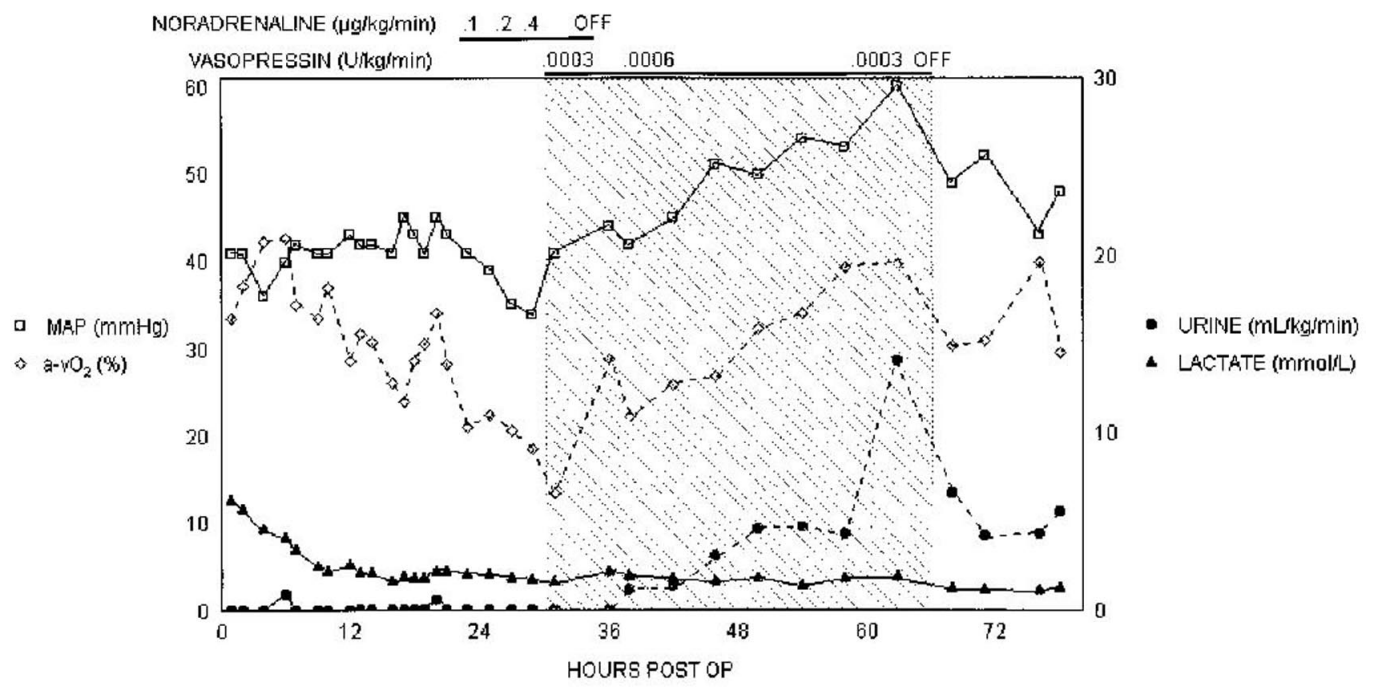

Figure 1. Line graph depicting mean arterial pressure in millimeters of mercury (open squares, numbers on axis to left), arterial-venous oxygen saturation difference as a percentage (open diamonds, numbers on axis to left), urinary output in milliliters per kilogram per minute (filled circles, numbers on axis to right), and serum lactate in millimoles per liter (filled triangles, numbers on axis to right) during early post operative period. Dose and timing for norepinephrine and vasopressin infusion are indicated above graph (bold lines). Hatched area represents duration of vasopressin infusion.

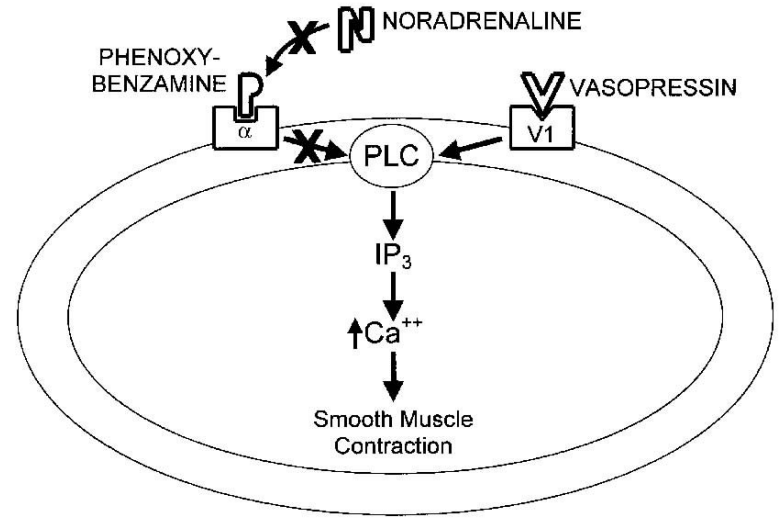

Figure 2. Diagrammatic representation of $\alpha$-adrenergic receptor $(\alpha)$ blockade by phenoxybenzamine. Because phenoxybenzamine is covalently bound to $\alpha$-adrenergic receptor, action of norepinephrine is blocked, phospholipase C (PLC) is not activated, and downstream signaling events required for smooth muscle cell contraction do not occur. In contrast, interaction of vasopressin with its receptor (V1) is not inhibited by phenoxybenzamine. Phospholipase $\mathrm{C}$ is activated and generates inositol triphosphate $\left(I P_{3}\right)$, which causes intracellular calcium $\left(\mathrm{Ca}^{++}\right)$release and vascular smooth muscle cell contraction. vasoconstriction or enhanced platelet aggregation that can occur at higher dosage. ${ }^{3}$ Although this experience represents only a single case, an understanding of the pharmacology of phenoxybenzamine suggests that vasopressin could be useful to modulate its effect, allowing more precise control of systemic vascular resistance and $\dot{\mathrm{Q}} / \mathrm{p}$. Further prospective investigation is necessary for definitive identification of the risks and benefits of this strategy.

\section{References}

1. Twedell JS, Hoffman GM, Fedderly RT, Berger S, Thomas JP, Ghanayem NS, et al. Phenoxybenzamine improves systemic oxygen delivery after the Norwood procedure. Ann Thorac Surg. 1999;67:161-8.

2. Hoffman BB, Lefkowitz RJ. Catecholamines, sympathomimetic drugs and adrenergic receptor antagonists: In: Hardman JG, Limbird LE, editors. Goodman \& Gilman's the pharmacologic basis of therapeutics. 9th ed. New York: McGraw-Hill; 1996. p. 227-8.

3. Holmes CL, Patel BM, Russell JA, Walley KR. Physiology of vasopressin relevant to management of septic shock. Chest. 2001;120:9891002.

4. Rosenzweig EB, Starc TJ, Chen JM, Cullinane S, Timchak DM, Gersony WM, et al. Intravenous arginine-vasopressin in children with vasodilatory shock after cardiac surgery. Circulation. 1999;100(19 Suppl):II182-6.

5. Birnbaumer M. Vasopressin receptors. Trends Endocrinol Metab. 2000;11:406-10. 